\title{
Yield of Combined Impedance-pH Monitoring for Refractory Reflux Symptoms in Clinical Practice
}

\author{
Georgios Karamanolis, ${ }^{1 *}$ Georgios Kotsalidis, ${ }^{1}$ Konstantinos Triantafyllou, ${ }^{1}$ Dimitrios Polymeros, ${ }^{1}$ Asimina Gaglia, \\ Smaragdi Fessatou, ${ }^{1}$ Maria Triantafyllou, ${ }^{1}$ loannis Papanikolaou ${ }^{1}$ and Spiros D Ladas ${ }^{2}$ \\ ${ }^{1}$ Hepatogastroenteroly Unit, 2nd Department of Internal Medicine - Propaedeutic, Attikon University General Hospital, Athens Medical School, \\ Athens, Greece, ${ }^{2}$ Hepatogastroenteroly Unit, 1 st Department of Internal Medicine - Propaedeutic, Laikon General Hospital, Athens Medical \\ School, Athens, Greece
}

\section{Background/Aims}

In patients with gastroesophageal reflux disease, persistent symptoms on proton pump inhibitor (PPI) therapy may be due to residual acid or non-acid reflux. Combined impedance-pH has been suggested to be superior to $\mathrm{pH}$ alone in the management of refractory patients to PPI. The utility of implementation of this technique in every day clinical practice is still unknown. The aim of this study was to investigate the outcomes of patients studied with combined impedance-pH and to evaluate the yield of additional impedance monitoring over $\mathrm{pH}$ alone in patients with persistent gastroesophageal reflux disease symptoms.

\section{Methods}

Seventy-one patients (31 men; mean age, $49.1 \pm 15.5$ years) on PPI therapy underwent combined impedance-pH for persistent typical (76\%) or atypical (49\%) symptoms.

\section{Results}

During impedance-pH study, 44 (62\%) patients reported symptoms. A positive symptom index (SI) was found in 21 (48\%) patients: $8(18.2 \%)$ had a positive SI for acid reflux, $9(20.5 \%)$ for non-acid reflux and $4(9.1 \%)$ for mixed reflux. Addition of impedance allowed association between reflux and symptoms in $20.5 \%$ of patients who would have been missed by $\mathrm{pH}$ study alone. Heartburn was the most prevalent symptom associated with acid reflux, whereas regurgitation and ear, nose and throat symptoms were associated with non-acid reflux.

\section{Conclusions}

The use of combined impedance-pH monitoring substantially increased the diagnostic yield compared to $\mathrm{pH}$ alone. With $\mathrm{SI}$ analysis, $20.5 \%$ of patients received a diagnosis that could not have been achieved with $\mathrm{pH}$ testing alone.

\section{(J Neurogastroenterol Motil 2011;17:158-163)}

Key Words

Electric impedance; Esophageal pH monitoring; Gastroesophageal reflux

Received: December 20, 2010 Revised: February 23, 2011 Accepted: February 25, 2011

(c) This is an Open Access article distributed under the terms of the Creative Commons Attribution Non-Commercial License (http://creativecommons org/licenses/by-nc/3.0) which permits unrestricted non-commercial use, distribution, and reproduction in any medium, provided the original work is properly cited.

*Correspondence: Georgios Karamanolis, MD

2nd Department of Internal Medicine - Propaedeutic, Attikon University General Hospital, Rimini 1, Haidari, Athens 12462, Greece

Financial support: None.

Tel: +30-210-5832090,Fax: +30-210-5326422,E-mail: georgekaramanolis@yahoo.co.uk

Conflicts of interest: None. 


\section{Introduction}

Gastroesophageal reflux disease (GERD) is a common disorder affecting approximately $35 \%-40 \%$ of the adult population. ${ }^{1,2}$ Proton pump inhibitors (PPIs) are the most potent agents for acid suppression and standard dose (once daily) of different PPIs has been established as providing symptom relief and healing of lesions in the majority of patients. ${ }^{3-6}$ Some patients require twice-daily PPI therapy, but may continue to experience GERD symptoms. ${ }^{6,7}$ It has been estimated that about $40 \%$ of GERD patients remain symptomatic despite treatment with PPIs. ${ }^{8}$ In these patients, ongoing symptoms may be caused by persistent acid reflux due to insufficient inhibition of gastric acid production, by "non-acid" reflux or by other causes that can be misinterpreted as GERD. ${ }^{9-12}$

In patients with persistent GERD symptoms despite acid suppression, current management algorithms propose $\mathrm{pH}$ monitoring under PPIs. ${ }^{13}$ However, recent studies challenged this approach showing that ambulatory $\mathrm{pH}$ monitoring has a low likelihood to be positive in this setting. ${ }^{14,15}$ The recently developed combined impedance-pH technology represents a better tool under these circumstances because it detects reflux of all types. ${ }^{10}$ Impedance monitoring has the ability to detect reflux episodes independent of the $\mathrm{pH}$ of the refluxate and concomitant $\mathrm{pH}$ recording determine their acidity classifying them as acidic or non-acidic. As non-acid reflux is considered a putative cause of ongoing symptoms despite PPI therapy, combined impedance$\mathrm{pH}$ monitoring seems to be the best strategy for evaluation of persistent reflux. It provides the same information as traditional $\mathrm{pH}$ monitoring and adds to it relevant information on the prevalence of non-acid reflux and its relation to refractory GERD symptoms.

The aim of our study was to evaluate the added yield of impedance-pH monitoring compared with conventional pH-metry in patients with persistent GERD symptoms on PPI in clinical practice.

\section{Materials and Methods}

\section{Study Population}

We analyzed 24 hour combined impedance-pH studies in patients who experienced persistent GERD-related symptoms while on PPI therapy. In addition, the daily dose of PPI (standard or double dose) and the presence of typical and atypical symptoms were analyzed in all patients. Heartburn, regurgitation and chest pain were considered typical symptoms, whereas pulmonary and ear, nose and throat (ENT) symptoms were included in atypical symptoms. All patients had a normal upper endoscopy. The study protocol was approved by the Attikon University General Hospital Institutional Review Board.

\section{Ambulatory Impedance-pH Monitoring}

A 6-channel impedance catheter (outer diameter $2.3 \mathrm{~mm}$ ) with attached $\mathrm{pH}$ recording at $5 \mathrm{~cm}$ above the manometrically localized lower esophageal sphincter was used. Before each study, the catheter was calibrated in buffer solutions of $\mathrm{pH} 7$ and 4 . For intraluminal impedance, the catheter enabled recordings from 6 segments, each recording segment being $2 \mathrm{~cm}$. The recording segments were located at 2-4, 4-6, 8-10, 10-12, 14-16 and 17-19 $\mathrm{cm}$ above the manometrically localized LES. The $\mathrm{pH}$ and impedance signals were stored in a digital system (Omega, MMS, Enschede, The Nederlands) using a sample frequency of 50 $\mathrm{Hz}^{16}$

\section{Study Protocol}

All patients underwent an upper endoscopy, followed by stationary esophageal manometry. Ambulatory 24 hour esophageal impedance-pH was performed on one of the next 7 days. Patients were required to be fasting for at least 6 hours before the procedure. Treatment with PPI was continued; all other drugs potentially affecting gastrointestinal motility and gastrointestinal secretion were discontinued at least 1 week prior to the study.

Data collection device, worn in a belt on the patient's waist, was connected to the catheter that had been introduced via nostril. Patients returned to their home and were instructed to continue their daily activities during the 24 hour measurement period. They were also asked to record a timetable of their meals and of time spending in upright and supine position on a diary card. Moreover, the occurrence of any symptom was recorded on patients' diary card.

\section{Data Analysis}

Combined impedance-pH data collected included any type of reflux episodes. For the analysis, the periods of meal consumption were marked and excluded. Reflux events were identified based on previously described criteria and classified as acidic or non-acidic using a threshold of $\mathrm{pH}=4 .^{9,10}$ The symptom index (SI) was calculated for each patient in relation to acid and 
non-acid reflux episodes. A symptom was considered to be associated with reflux if it was preceded within 2 minutes by a reflux episode. ${ }^{17}$ A positive SI was defined if $>50 \%$ of the symptoms were associated with reflux. ${ }^{18}$ Impedance-pH monitoring was considered pathological when a positive SI was present.

\section{Statistical Methods}

Values are expressed as mean $\pm \mathrm{SD}$. Statistical analysis was performed by Student's $t$ test or Chi-square testing wherever appropriate. $P$-value $<0.050$ was were considered to be significant.

\section{Results}

\section{Patient Characteristics}

Seventy-one patients ( 31 men; mean age, $49.1 \pm 15.5$ years) with refractory reflux symptoms underwent a 24 hour combined impedance-pH monitoring under PPI therapy. Forty-two (59\%) patients were treated with standard PPI dose and 29 (41\%) with double PPI dose. Fifty-four (76\%) patients had typical symptoms, while 35 (49\%) patients had atypical symptoms.

\section{Impedance-pH Monitoring}

Forty-four (62\%) patients reported symptoms during the 24 hour impedance-pH study; 30 patients were on standard and 14 on double PPI dose. Heartburn (34\%) was the most common symptom reported, following by ENT and regurgitation (19\%, respectively) while chest pain and pulmonary symptoms were re-

Table 1. Reflux Parameters and Symptoms of Symptomatic Patients on Standard and on Double Proton Pump Inhibitor Dose

\begin{tabular}{lccc}
\hline & $\begin{array}{c}\text { Standard } \\
\text { PPI dose }\end{array}$ & $\begin{array}{c}\text { Double } \\
\text { PPI dose }\end{array}$ & $P$-value \\
\hline Number (\%) & $30(71.4)$ & $14(42.3)$ & 0.048 \\
Age (yr) & $48.1 \pm 14.5$ & $50.0 \pm 15.7$ & 0.249 \\
Gender (male/female) & $14 / 16$ & $5 / 9$ & 0.245 \\
Total number of reflux & $41.3 \pm 20.0$ & $33.6 \pm 18.9$ & 0.229 \\
Number of acid reflux & $14.3 \pm 13.7$ & $11.6 \pm 8.4$ & 0.416 \\
Percentage of time pH $<4$ & $5.5 \pm 9.1$ & $4.3 \pm 7.6$ & 0.662 \\
Heartburn (n [\%]) & $15(71.3)$ & $9(50)$ & 0.170 \\
Regurgitation (n [\%]) & $11(73.3)$ & $2(33.3)$ & 0.088 \\
Chest pain (n [\%]) & $4(44.4)$ & $5(71.4)$ & 0.280 \\
ENT symptoms (n [\%]) & $11(78.6)$ & $2(66.7)$ & 0.659 \\
Pulmonary symptoms (n [\%]) & $8(61.5)$ & $1(16.7)$ & 0.068 \\
\hline
\end{tabular}

PPI, proton pump inhibitor; ENT, ear, nose and throat. ported by $14 \%$ of patients.

\section{Standard vs Double Proton Pump Inhibitor Dose}

The proportion of patients reporting symptoms were higher in those on standard PPI compared to those on double dose (30/42 vs $14 / 29, P=0.048$ ). The age and sex were similar between patients on standard and on double PPI dose (Table 1). Among symptoms, regurgitation and pulmonary symptoms were reported more frequent by patients on once PPI daily, although the difference was not statistically significant. The percentage time of a $\mathrm{pH}<4$ was similar in patients on standard compared to those on double PPI dose (5.5 \pm 9.1 vs $4.3 \pm 7.6$, respectively). There was no statistically significant difference in the mean number of total reflux episodes that occurred during the study (41.3 \pm 20.0 on standard dose vs $33.6 \pm 18.9$ on double dose, $P=$ $0.220)$ and in the mean number of acid reflux episodes (14.3 \pm 13.7 on standard dose vs $11.1 \pm 8.4$ on double dose, $P=0.416$ ), as well.

\section{Symptom Index Analysis}

From 44 patients, a positive SI for at least 1 of patients' symptom was found in 21 (48\%) patients. Eleven (52\%) patients had a positive SI for 1 symptom, 8 (38\%) patients for 2 and 2 patients $(10 \%)$ for 3 symptoms. The PPI medication dose was similar between patients with and without positive SI (Table 2). Heartburn was the most prevalent symptom associated with reflux episodes, followed by regurgitation and ENT symptoms

Table 2. Demographic Characteristics and Symptoms Reported by Patients With and Without Positive Symptom Index

\begin{tabular}{lccc}
\hline & SI $(+)$ & SI $(-)$ & $P$-value \\
\hline Number & 21 & 23 & \\
Age (yr) & $48.1 \pm 14.5$ & $50.0 \pm 15.7$ & 0.680 \\
Gender (male/female) & $10 / 11$ & $10 / 13$ & 0.782 \\
PPI dose (n [\%]) & & & \\
$\quad$ Standard & $15(71.4)$ & $15(65.2)$ & 0.658 \\
$\quad$ Double & $6(28.6)$ & $8(34.8)$ & 0.658 \\
Typical symptoms (n [\%]) & $17(81)$ & $17(74)$ & 0.577 \\
$\quad$ Heartburn & $11(52)$ & $13(57)$ & 0.782 \\
$\quad$ Regurgitation & $7(33)$ & $6(26)$ & 0.598 \\
$\quad$ Chest pain & $4(19)$ & $5(22)$ & 0.825 \\
Atypical symptoms (n [\%]) & $10(48)$ & $11(48)$ & 0.989 \\
$\quad$ ENT & $7(33)$ & $6(26)$ & 0.598 \\
$\quad$ Pulmonary & $3(14)$ & $6(26)$ & 0.332 \\
\hline
\end{tabular}

SI, symptom index; PPI, proton pump inhibitor; ENT, ear, nose and throat. 


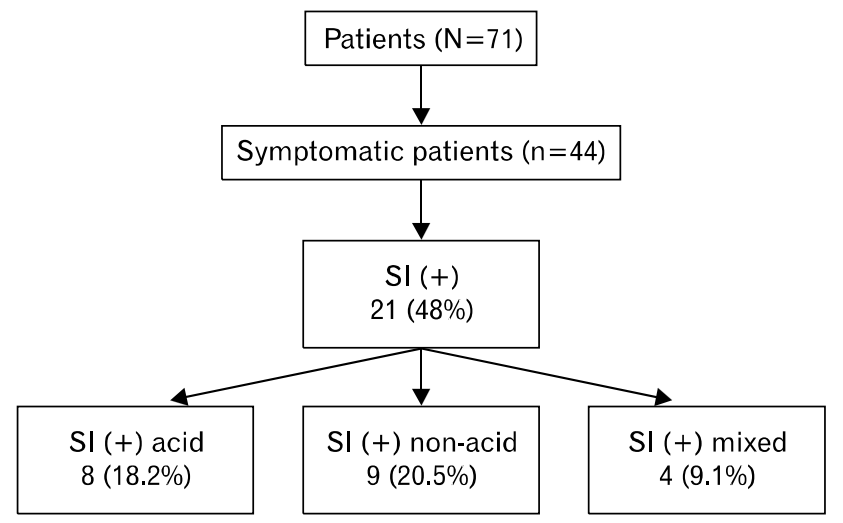

Figure. Combined impedance-pH monitoring in 71 patients on proton pump inhibitor therapy. SI, symptom index.

(Table 2). Regarding the frequency of reported symptoms in patients with or without positive SI, there was no statistically significant difference between typical and atypical symptoms as a whole and among any of the individual symptoms.

Of the 21 patients with an overall positive SI, 8 (18.2\%) had a positive SI for acid reflux, 9 (20.5\%) for non-acid reflux and 4 (9.1\%) for mixed reflux (Figure). Thus, addition of impedance allowed association between reflux and symptoms in $20.5 \%$ of patients who would have been missed by a $\mathrm{pH}$ study alone. Evidence consistent with acid reflux as a cause of symptoms was found in $27.3 \%$ of patients, whereas a temporal association between non-acid reflux and symptoms was present in $29.6 \%$ of patients. As indicated in Table 3, heartburn was the most prevalent symptom associated with acid reflux, whereas regurgitation and ENT symptoms were associated with non-acid reflux.

\section{Discussion}

In patients with GERD symptoms refractory to PPI therapy, 24 hour $\mathrm{pH}$ testing is still considered the gold standard method to diagnose reflux. ${ }^{13}$ However, recent studies challenged this approach showing that ambulatory $\mathrm{pH}$ monitoring in patients refractory to PPI therapy was most likely to be normal. ${ }^{14,15}$ Combined impedance-pH monitoring has recently received worldwide interest because of its ability to detect not only acid but also all types of reflux. As the main concern in patients with refractory symptoms to PPI is whether or not their symptoms are brought about by reflux, we used SI as the method that can establish a correlation between reflux and symptoms.

Our results showed that $48 \%$ of patients on PPI therapy had a positive SI for all types of reflux. A positive SI for acid reflux
Table 3. Symptom-Reflux Association in 44 Symptomatic Patients on Proton Pump Inhibitor

\begin{tabular}{lccc}
\hline & Patients & $\begin{array}{c}\text { Acid-reflux } \\
\text { SI }(+)\end{array}$ & $\begin{array}{c}\text { Non-acid reflux } \\
\text { SI }(+)\end{array}$ \\
\hline Typical (n) & 34 & 6 & 11 \\
$\quad$ Heartburn & 24 & 6 & 5 \\
Regurgitation & 13 & 2 & 5 \\
Chest pain & 9 & 1 & 3 \\
Atypical (n) & 21 & 4 & 6 \\
$\quad$ ENT & 13 & 2 & 5 \\
Pulmonary & 9 & 2 & 1 \\
\hline
\end{tabular}

SI, symptom index; ENT, ear, nose and throat.

was found in only $27.3 \%$ of these patients. In our population, non-acid reflux was considered as the cause of symptoms in $20.5 \%$ of patients. Thus, before the advent of combined impedance-pH, this proportion of patients would have been identified as negative for GERD and represents the increased diagnostic yield of this technique compared with $\mathrm{pH}$ study alone. Our results are similar to a multicenter study of 168 refractory GERD patients, in which a positive SI for non-acid reflux was found in $37 \%{ }^{11}$ A French-Belgian cohort study also revealed that the addition of impedance resulted in a considerable overall diagnostic gain of $16.7 \%$ in patients on PPI. ${ }^{12}$ In addition, a recent study showed that $39 \%$ of patients on double daily PPI therapy had a positive SI for non-acid reflux and would have been misdiagnosed by a $\mathrm{pH}$-alone study. ${ }^{19}$ The combination of conventional $\mathrm{pH}$ monitoring with impedance was also helpful in identifying non-erosive reflux disease patients off the medication who had a positive symptom association for non-acid reflux. Without impedance addition, this subgroup of patients would have been labelled as having functional heartburn. ${ }^{20}$ In a recently published study, Blonski et $\mathrm{al}^{21}$ underlined the clinical importance of non-acid reflux showing that the maximal rate of reflux episodes was the same whether patients were taking medication or not.

Heartburn has traditionally been accepted as the most frequent acid-mediated symptom, and we indeed found that heartburn was the most prevalent symptom associated with acid reflux. Regurgitation and ENT symptoms were the most common manifestations in patients with non-acid reflux. In the literature there was conflicting results regarding regurgitation; Zerbib et $\mathrm{al}^{12}$ reported a positive association of regurgitation and non-acid reflux, while Kline et $\mathrm{al}^{22}$ found that regurgitation accounted for $64 \%$ of symptoms in the acid-reflux group of patients. For ENT symptoms, it is widely accepted that it is unlikely to related with acid 
reflux. ${ }^{23}$ Non-acid reflux triggering ENT symptoms is a concept that has gained interest and our results support the hypothesis that non-acid reflux could be the cause of ENT symptoms. Although our finding is very promising, we should keep in mind that the cause and effect relationship between atypical symptoms and reflux is difficult to be established. Thus, a study including more patients should have to confirm our results, as only a minority of our patients had ENT symptoms.

Once GERD has been established as a diagnosis, the next step will be to determine the response to various therapies for the patient. In patients with pathological acid exposure, a shift to a different PPI, an addition of a nighttime histamine-2 receptor antagonist or increase of PPI dose could yield a better response rate. $^{24,25}$ In patients with non-acid or mixed reflux potential therapies would include medical therapies, such as baclofen, endoscopic therapy and surgical treatment.

Our study showed that $52 \%$ of patients reporting symptoms during the impedance-pH monitoring did not have evidence of an association of GERD-like symptoms with any type of reflux events. This information has clinical importance because this finding indicates that other causes, such as functional disorders of the esophagus or hypersensitivity to different stimuli, should be investigated. Our results are similar to previously published studies; a proportion of patients (ranged from $19 \%$ to $58 \%$ ) who experienced symptoms during the study day had no evidence consistent with reflux as a cause of these symptoms. ${ }^{12,19-22}$

A limitation of our study is the fact that our study population was a mixed cohort regarding medication use, with $59 \%$ on single dose of PPI. Thus, someone can argue that these patients may not represent the standard patient who should undergo further investigation with 24 hour impedance-pH monitoring. However, population of patients included in the study is representative of every day patients referred to our unit with symptoms presumed due to GERD.

In conclusion, our study showed that combined impedancepH monitoring significantly increased the diagnostic yield of persistent pathological reflux compared to $\mathrm{pH}$ alone in GERD patients refractory to PPI therapy. With SI analysis, $20.5 \%$ of patients received a diagnosis that could not have been achieved with pH testing alone.

\section{References}

1. Isolauri J, Laippala P. Prevalence of symptoms suggestive of gastroesophageal reflux disease in an adult population. Ann Med 1995; 27:67-70.
2. Nebel OT, Fornes MF, Castell DO. Symptomatic gastroesophageal reflux: incidence and precipitating factors. Am J Dig Dis 1976; 21:953-956.

3. Kahrilas PJ, Shaheen NJ, Vaezi MF; American Gastroenterological Association Institute; Clinical Practice and Quality Management Committee. American Gastroenterological Association Institute technical review on the management of gastroesophageal reflux disease. Gastroenterology 2008;135:1392-1413.

4. Hetzel DJ, Dent J, Reed WD, et al. Healing and relapse of severe peptic esophagitis after treatment with omeprazole. Gastroenterology 1988;95:903-912.

5. Sontag SJ, Hirschowitz BI, Holt S, et al. Two doses of omeprazole versus placebo in symptomatic erosive esophagitis: The U.S. Multicenter Study. Gastroenterology 1992;102:109-118.

6. Klinkenberg-Knol EC, Festen HP, Jansen JB, et al. Long-term treatment with omeprazole for refractory reflux esophagitis: efficacy and safety. Ann Intern Med 1994;121:161-167.

7. Leite LP, Johnston BT, Just RJ, Castell DO. Persistent acid secretion during omeprazole therapy: a study of gastric acid profiles in patients demonstrating failure of omeprazole therapy. Am J Gastroenterol 1996;91:1527-1531.

8. Dean BB, Gano AD Jr, Knight K, Ofman JJ, Fass R. Effectiveness of proton pump inhibitors in nonerosive reflux disease. Clin Gastroenterol Hepatol 2004;2:656-664.

9. Vela MF, Camacho-Lobato L, Srinivasan R, Tutuian R, Katz PO, Castell DO. Simultaneous intraesophageal impedance and $\mathrm{pH}$ measurement of acid and non-acid gastroesophageal reflux: effect of omeprazole. Gastroenterology 2001;120:1599-1606.

10. Sifrim D, Castell D, Dent J, Kahrilas PJ. Gastroesophageal reflux monitoring: review and consensus report on detection and definitions of acid, non-acid, and gas reflux. Gut 2004;53:1024-1031.

11. Mainie I, Tutuian R, Shay S, et al. Acid and non-acid reflux in patients with persistent symptoms despite acid suppressive therapy: a multicentre study using combined ambulatory impedance-pH monitoring. Gut 2006;55:1398-1402.

12. Zerbib F, Roman S, Ropert A, et al. Esophageal pH-impedance monitoring and symptom association analysis in patients off and on therapy. Am J Gastroenterol 2006;101:1956-1963.

13. DeVault KR, Castell DO; American College of Gastroenterology. Updated guidelines for the diagnosis and treatment of gastroesophageal reflux disease. Am J Gastroenterol 2005;100:190-200.

14. Charbel S, Khandwala F, Vaezi MF. The role of esophageal $\mathrm{pH}$ monitoring in symptomatic patients on PPI therapy. Am J Gastroenterol 2005;100:283-289

15. Karamanolis G, Vanuytsel T, Sifrim D, et al. Yield of 24-hour esophageal $\mathrm{pH}$ and Bilitec monitoring in patients with persistent symptoms on PPI therapy. Dig Dis Sci 2008;53:2387-2393.

16. Bredenoord AJ, Weusten BL, Timmer R, Smout AJ. Minimum sample frequency for multichannel intraluminal impedance measurement for the oesophagus. Neurogastroenterol Motil 2004;16:713719 .

17. Lam HG, Breumelhof R, Roelofs JM, Van Berge Henegouwen GP, Smout AJ. What is the optimal time window in symptom analysis of 24-hour esophageal pressure and $\mathrm{pH}$ data? Dig Dis Sci 1994;39: 402-409.

18. Bredenoord AJ, Weusten BL, Smout AJ. Symptom association anal- 
ysis in ambulatory gastro-oesophageal reflux monitoring. Gut 2005;54:1810-1817.

19. Sharma N, Agrawal A, Freeman J, Vela MF, Castell D. An analysis of persistent symptoms in acid-suppressed patients undergoing impedance-pH monitoring. Clin Gastroenterol Hepatol 2008;6:521524.

20. Savarino E, Zentilin P, Tutuian R, et al. The role of nonacid reflux in NERD: lessons learned from impedance-pH monitoring in 150 patients off therapy. Am J Gastroenterol 2008;103:2685-2693.

21. Blonski W, Vela MF, Castell DO. Comparison of reflux frequency during prolonged multichannel intraluminal impedance and $\mathrm{pH}$ monitoring on and off acid suppression therapy. J Clin Gastroenterol 2009;43:816-820.

22. Kline MM, Ewing M, Simpson N, Laine L. The utility of intra- luminal impedance in patients with gastroesophageal reflux disease-like symptoms but normal endoscopy and 24-hour $\mathrm{pH}$ testing. Clin Gastroenterol Hepatol 2008;6:880-885.

23. Joniau S, Bradshaw A, Esterman A, Carney AS. Reflux laryngitis: a systematic review. Otolaryngol Head Neck Surg 2007;136:686-692.

24. Xue S, Katz PO, Banerjee P, Tutuian R, Castell DO. Bedtime H2 blockers improve nocturnal gastric acid control in GERD patients on proton pump inhibitors. Aliment Pharmacol Ther 2001;15:13511356.

25. Becker V, Bajbouj M, Waller K, Schmid RM, Meining A. Clinical trial: persistent gastro-oesophageal reflux symptoms despite standard therapy with proton pump inhibitors - a follow-up study of intraluminal-impedance guided therapy. Aliment Pharmacol Ther 2007; 26:1355-1360. 